\title{
MERGANSERS AND RESORTS
}

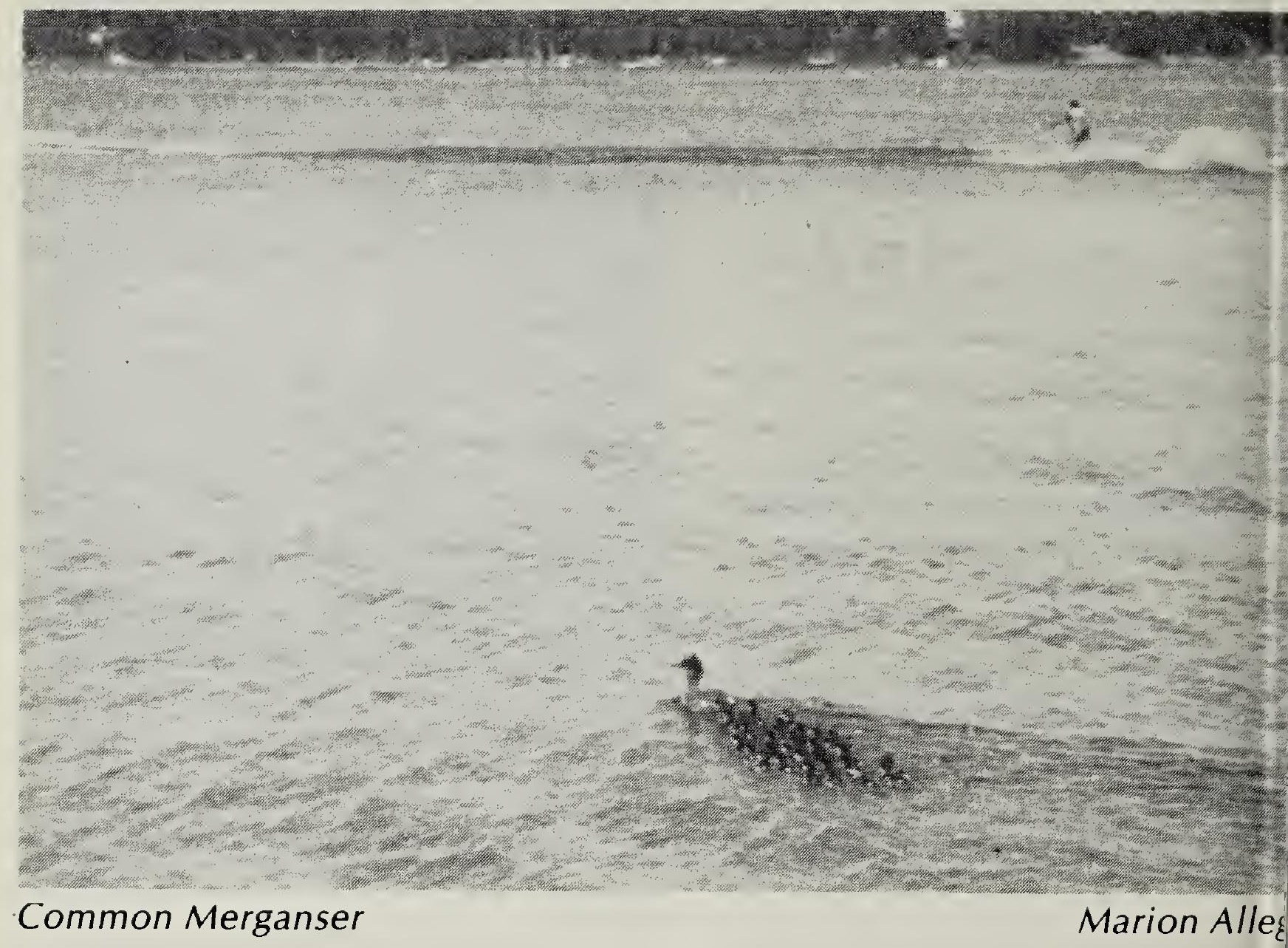

Taken at Emma Lake 1 July 1988, this photograph makes two statements, one about mergansers, the other about today's resort environment.

The Common Merganser may lay up to 17 eggs, although the usual clutch is 9 to 12 . Examination, however, of a large color print under strong light and magnifying glass showed 20 ducklings, four larger than the others, indicating there had been two broods. Possible explanations were coalesced broods, partial brood adoption or surrogate parent, all occasional behaviourisms by this species. Because Emma is at the southerly limit of the breeding range, merganser broods have been uncommon on the lake, and are even rarer today. The photo-record is noteworthy.
Since the mid-1950s, resort acti this lake has increased markedly; usage, reed bed clearing and sho cottage development now mean water-associated birds. For those that do settle in during spring wh lake is still quiet, the reproducti, quence is often disturbed, for st with the first warm weekends, $h$ activity becomes considerable photo tells it all.

Alvena Schnell brought photograph to my attention; Dzubin made available referenc brood formation. - jim A. Wedg 610 Leslie Avenue, Saskatoon, atchewan.S7H $2 \mathrm{Z} 2$ 